\title{
Verification of RFID System Usability in Silage Bale Life
}

\section{Cycle Management}

\author{
Katariina Penttilä ${ }^{1}$, Antti Suokannas ${ }^{2}$ and Ilpo Pölönen ${ }^{3}$ \\ 1. Energy Efficiency Research Group, HAMK Tech Research Unit, Häme University of Applied Sciences, Lotilantie 16, 37630 \\ Valkeakoski, Finland
}

2. Production Systems, Natural Resources Institute Finland, Maarintie 6, 02150 Espoo, Finland

3. Bioeconomy Research Unit, Häme University of Applied Sciences, PL 230, 13101 Hämeenlinna, Finland

\begin{abstract}
Digitalization has nowadays raised interest in variable applications of farming. Increase of knowledge level, by means of unique identification, automation and control, farmers gain relevant business profit. This research is focused on the utilization of passive radio frequency identification (RFID) technology in silage bale application, both manual and automated level. Challenges arise due to silage conservation, varying environmental and seasonal conditions, different identification environments and RFID operation principle. Further maximum communication signal strength is limited by telecommunication standard regulations (e.g., ETSI). The applicability of RFID technology with different commercial passive transponders is measured manually in a silage bale of $160 \mathrm{~cm}$ in diameter, covering 360 degrees around the bale. In addition, automated field tests are conducted in a real environment, where the data collection system is appended to a tractor and RFID reader antenna in a baler. Manual measurements are conducted as identification distance (meters) and transponder population (number of tags), while automated measurements are based on the number of successfully identified silage bales. Based on the manual measurement results, the most suitable tags for the automated field measurements were chosen, and the applicability to silage bale identification was verified. Field tests showed $100 \%$ success, with 151/151 uniquely identified silage bales. Achieved results prove that passive RFID operates well enough in silage bale identification, further enabling the development of digitalization of silage bale life cycle.
\end{abstract}

Key words: Digibale, silage bale life-cycle management, radio frequency identification, digitalization of silage bale, unique identification.

\section{Introduction}

Digitalization and Internet of Things (IoT) have gained interest across all commercial sectors. Many potential applications have been introduced, but in most cases, commercial side and practical benefits have forgotten. This paper focuses on digitalization of silage bale life cycle, having its origins in business needs. Digitalization has foundations in unique identification, where passive radio frequency identification (RFID) technology was chosen as a potential identification methodology due to its wireless and non-line of sight operation principle. By integrating existing technologies and an application

Corresponding author: Katariina Penttilä, Ph.D., research fields: metrology, RFID, ecological technology, energy efficiency. software in a new fashion, a new concept and implementation of automated unique identification and tracking of silage bales, bale bookkeeping and open marketplace are created to modernize silage bale farming sector.

The first phase of this research project is to choose and verify unique identifiers, i.e., transponders for silage bale identification throughout bales' life cycle and define most appropriate system arrangements in a baler. This paper introduces the principles and results achieved in that research: first RFID operation principle in application is described, then passive transponders' performance is evaluated in stationary conditions, and finally automated field tests are described, evaluated and analyzed against the application needs. 


\subsection{Silage Bales}

In Finland, silage bales are conserved from fall until up to springtime, even to next fall sometimes. They are wrapped with bale net and further multiple plastic layers. Most of silage bales are stored in stacks on the edge of field or near cowshed without any special tag identification. Spray paint may be used for identifying the bales. These markings may be elapsed during the storage period, by making it impossible to track and identify bales, and combine them to the typically used manual bookkeeping. Bales are subjected to variable weather conditions as warm sunshine, cold, rain, snow and frost, repeating multiple times during storage. Further, birds or rodents can cause holes to plastic layers of silage bales. Therefore, the bale identifiers, now RFID transponders must be placed inside the bale wrappings. However, as silage bale conservation is based on lactic acid fermentation, with $\mathrm{pH}$ around four and dry matter variation between $20 \%$ and $45 \%$ [1], the challenge of radio wave propagation in such environment arises.

Typical silage bale size varies between 1,300 mm and 1,600 $\mathrm{mm}$ in diameter. They are handled with pallet trucks in random orientation. Therefore, the ultimate target would be in achieving identification coverage of 360 degrees around the bale. This paper introduces the first steps to achieve this, by reviewing and analyzing passive RFID tag measurements in the silage bale application.

\subsection{Digibale Concept}

Digibale concept is a concept enabling unique bale identification, collecting microclimate information, analyzing bale related data, managing bale storages, and also selling and buying silage bales in open application platform. Fig. 1 presents the work packages (WPs) of Digibale project, launched for implementing the concept [2]. The following describes WPs shortly:

WP1: Background data collection, benchmarking and foundations

- to collect information about the life-cycle management of bales' lifecycle;

- seek information on which parameters are important for the target audience;

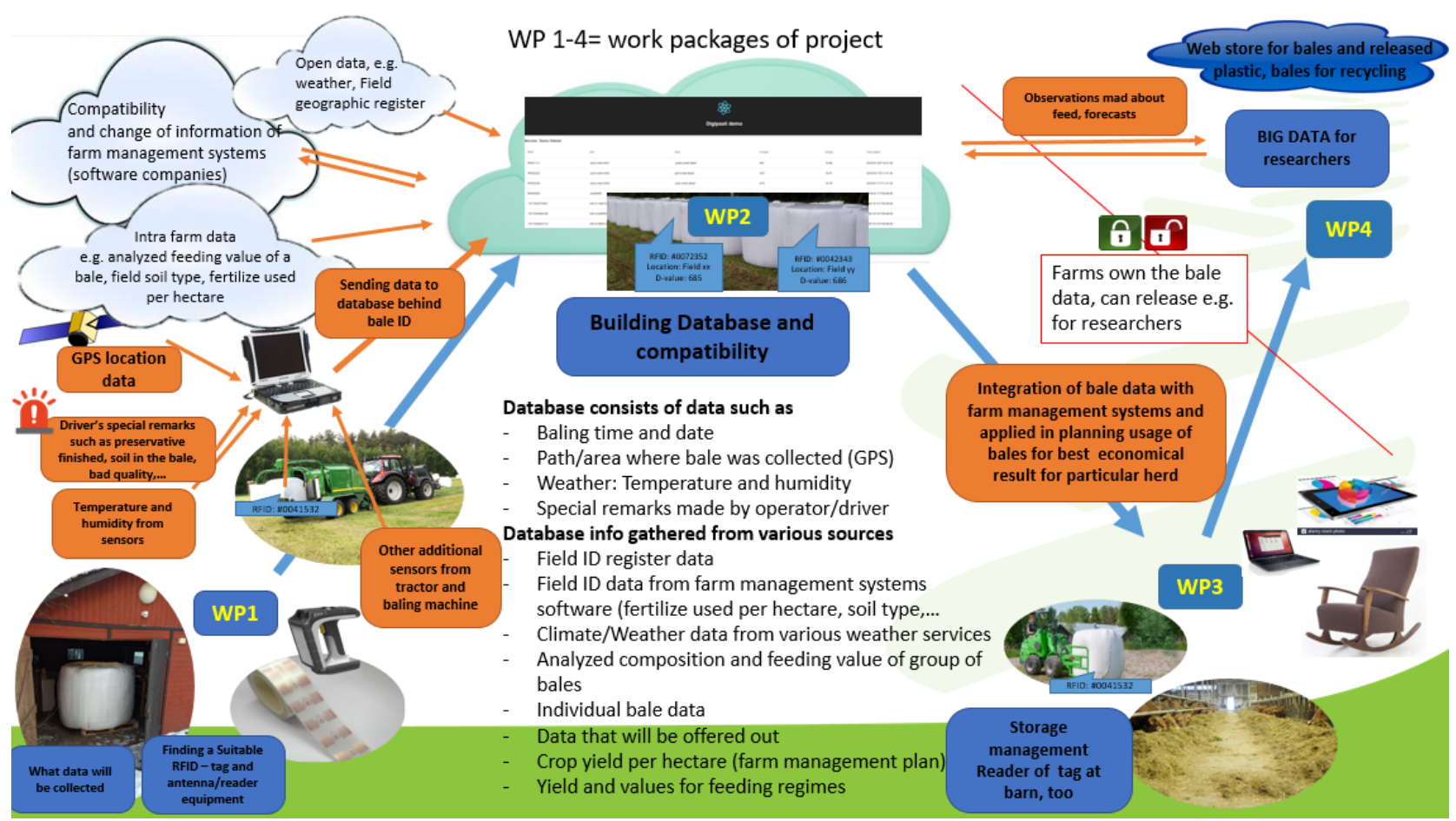

Fig. 1 Schema of Digibale concept [2]. 
- hardware and network connections: microclimate measurements, RFID reader and tags, database connection, supply in baler machine;

- initial acceptance testing.

WP2: Building database and compatibility

- develop the unique marking of bales;

- collect and export the status and location data to the database;

- field testing with baler machine.

WP3: Collection and use of data

- collect, analyze and combine binary identification, location and measurement data for internal and external;

- data sources;

- user interfaces for different purposes.

WP4: Business and service design

- web store;

- own data for farmers;

- big data for researchers.

This paper focuses on WP1, primarily RFID performance measurements.

\subsection{Principle of RFID Technology}

RFID technology is an identification technology that uses radio waves for communication. Typical operational frequencies are $865-868 \mathrm{MHz}$ in Europe and $13.56 \mathrm{MHz}$ globally [3]. The first one is based on electromagnetic waves, enabling long-range identification, while the latter is based on magnetic coupling, and operates only in near field. Some commonly known RFID applications are key cards, passports, library anti-theft systems, near field payment and metro tickets.

The operation principle of passive RFID is based on backscattering technology [4-6]. Passive technology means that the transponders do not have any kind of internal power source, but it harvests its operational energy from the reader's transmission signal $[7,8]$. RFID reader, with external or integrated antenna, is connected to backend system and operates as master towards transponders. Based on application needs, reader sends identifier polling request to its surroundings. Regional institutes, such as European Telecommunication Standards Institute (ETSI) limit the maximum allowed transmitted power level. Depending on the radiation pattern of the antenna, the reader's request will spread either a narrower or a wider area, while the total amount of radiated power shall be under specified limit. If any transponder exists inside the range, the reader transmission signal will first wake the tag up, then give the identifier reading command and finally send some unmodulated signal, which the transponder will modulate and reflect backwards [9-11]. The transponder modulation, which is fully passive, is based on switch connection inside transponder microchip. The modulation is on-off type amplitude modulation [7]. Communication principle is introduced in Fig. 2.

While magnetic coupling enables identification ranges up to around $1 \mathrm{~m}$, ultra-high frequency (UHF) RFID at around $866.5 \mathrm{MHz}$ enables identification distances up to around $10 \mathrm{~m}[12,13]$. These distances are maximum free air distances, meaning, that between the reader antenna and the transponder, there is only free air, without any obstacles. All absorbing materials, such as concrete wall structures, attenuate the radio signal and diminish the identification distance. In addition, the material, where the transponder is attached to, influences to the achievable identification distance. All absorbing or reflecting base materials will attenuate the communicating signal, and therefore diminish the identification distance. Absorption means that the material itself absorbs radio waves causing diminishing the maximum peak intensity [14, 15]. Reflecting occurs when the radio wave is reflected from the base surface, and then eloped away [16-19]. As in the application at hand, the transponder base has strong humidity level and large humidity variation, being between 20\%-45\% [1], the wrapped silage bale becomes conductive, sharing both absorbing and reflecting properties. Large humidity value leads to high conductivity [14, 15], further 


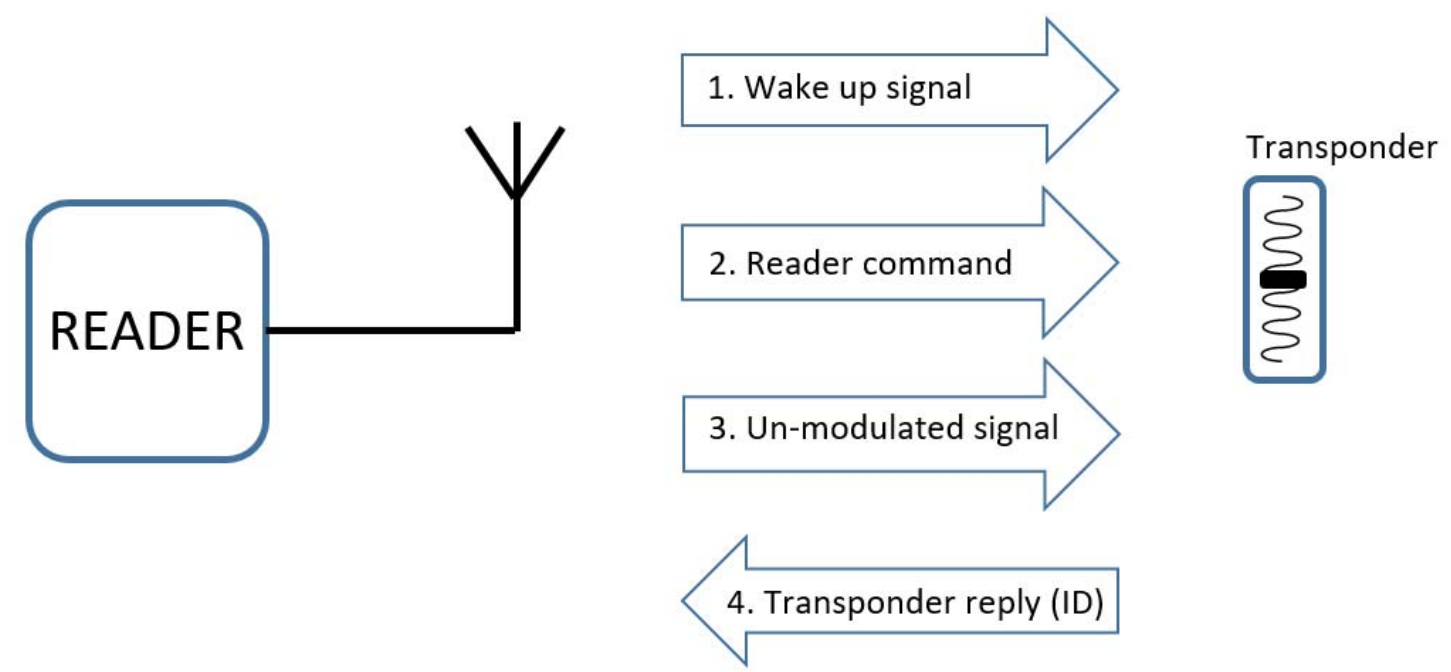

Fig. 2 Radio frequency identification (RFID) reader-transponder communication principle.

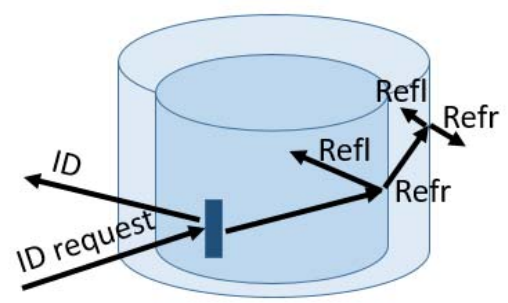

Silage

Plastic wrapping

Transponder between

silage and wrapping

Radio wave

Refl $=$ reflection

Refr $=$ refraction

Fig. 3 Illustration of reflection and refraction principles in silage bale application.

causing strong wave propagation in the bale, which diminish the amount of radio wave reaching the transponder, and therefore diminishing the identification distance. The radio wave propagated inside the silage bale will quickly reach the edge of the bale, and then will partially reflect back to the bale, and partially refract to the plastic wrapping and further outside air. In addition, part of the radio wave will propagate as a surface wave along the silage and further causing improved identification performance at a certain angle, which are not perpendicular to the reader antenna, but at a slight angle compared to that. Fig. 3 presents reflection and refraction phenomena in silage bale application. To conclude, radio frequency identification in silage bale application requires that transponder has strong ability to harvest and backscatter radio waves in challenging environment [20-23].

\section{Materials and Methods}

This paper examines the performance of passive RFID in silage bale application. In order to conduct required measurements, this chapter introduces and arguments chosen technologies and methodology.

\subsection{Initial Tests and Test Results}

Initial tests were taken to find out the best performing passive transponder. Totally four 
potential transponder types with different microchips were tested and measured in terms of free air reading distance. Tests were taken in laboratory conditions. Then the best performing transponders were chosen for application measurements. Fig. 4 introduces the pictures of each tested transponder types. The choices of these transponders were based on manufacturer and retailer's recommendations.

The initial transponder test results are presented in Table 1. Results show that the Dogbone 425-1 shows best performance, and therefore it was selected for application measurements.

\subsection{RFID Components}

Radio frequency identification components were chosen based on performance criteria and integration to the baler application. Based on initial tests, Dogbone 425-1 transponders were chosen for first silage bale measurements. This transponder is presented in bottom left, in Fig. 4. In final application, three different readers are chosen to enable various different identification positions in

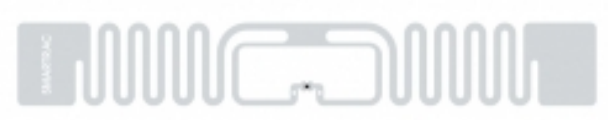

(a)

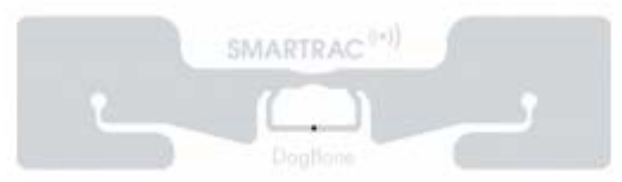

(c) the Digibale application concept. For both initial test and the first bale measurements, Speedway UHF RFID reader was used consistently.

\subsection{Manual Measurements: Methodology}

Application measurements were taken outside, with real silage bale, as shown in Fig. 5a. Small holes were cut on the bale wrapping, and the chosen transponders were placed under the plastic wrapping. Before measurements, the cuttings were sealed with high quality tape to confirm that microclimate inside the silage bale wrapping remains as close as possible to the original. Cutting the bale is introduced in Fig. 5b. Totally eight transponders, shown in Fig. 6, were placed inside bale wrapping with even steps, to fulfilling the 360 degrees around the bale. Fig. 7 shows the measurement arrangement, and directions of wave propagation between transponder and reader antenna. The positions 4, 5 and 6 in Fig. 7 (numbered positions in the figure) are located in a way that the radio wave will propagate through the silage bale, which causes multiple reflection and refraction points presented in Fig. 3 [24-26].

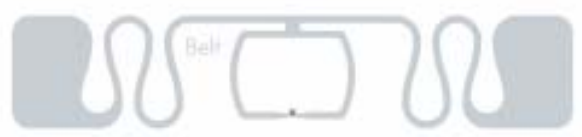

(b)

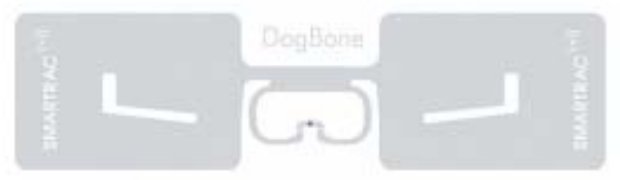

(d)

Fig. 4 Belt 387-1 (a), Belt 285-3 (b), Dogbone 425-1 (c) and Dogbone 391-2 (d).

Table 1 Transponder free air test results.

\begin{tabular}{lllll}
\hline Transponder type & $\begin{array}{l}\text { Free air reading distance in } \\
\text { laboratory conditions in 0 degree } \\
\text { angle towards the reader antenna, }\end{array}$ & $\begin{array}{l}\text { Free air reading distance in } \\
\text { laboratory conditions in 90 degrees } \\
\text { angle towards the reader antenna, } \mathrm{m}\end{array}$ & Microchip type & $\begin{array}{l}\text { Transponder size, } \\
\mathrm{mm} \times \text { mm }\end{array}$ \\
\hline Belt 387-1 & 2.6 & 3.0 & G2IL & $70 \times 10$ \\
Belt 285-3 & 2.5 & 2.6 & Monza 6 & $70 \times 14$ \\
Dogbone 425-1 & 6.8 & 7.2 & Monza R6 & $94 \times 24$ \\
Dogbone 391-2 & 6.4 & 4.6 & Ucode7 & $94 \times 24$ \\
\hline
\end{tabular}




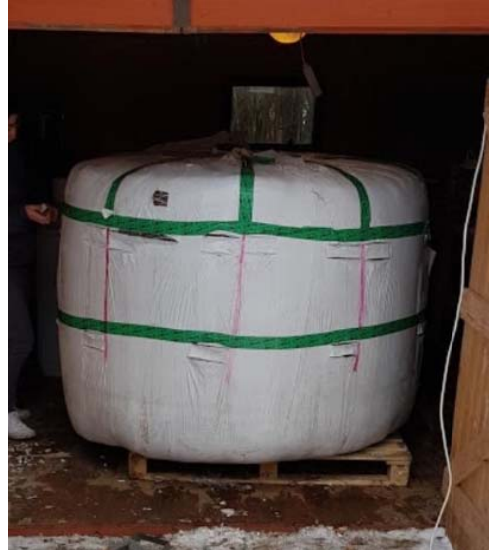

(a)

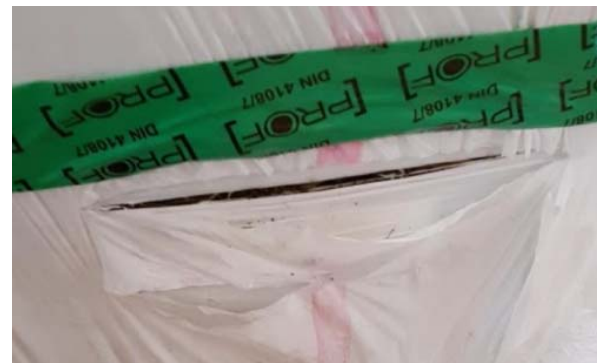

(b)

Fig. 5 Silage bale: (a) test bale (left); (b) bale cut (right).
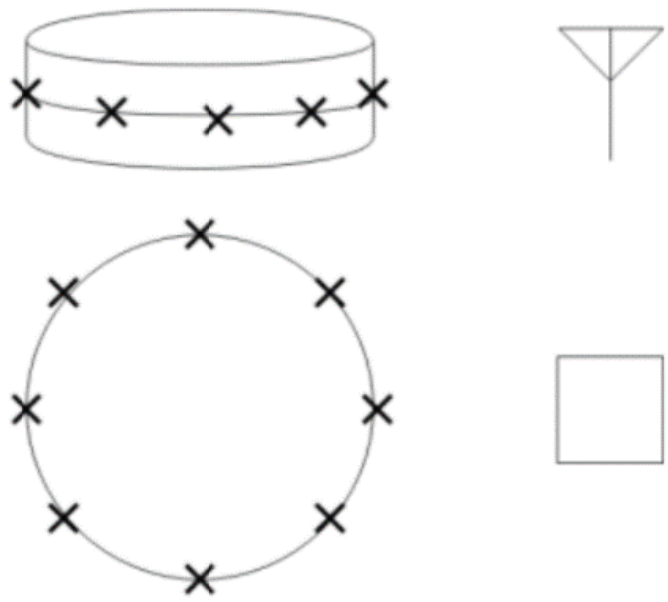

Fig. 6 Schematic view of transponder placements in bale (top: side view; bottom: top view).

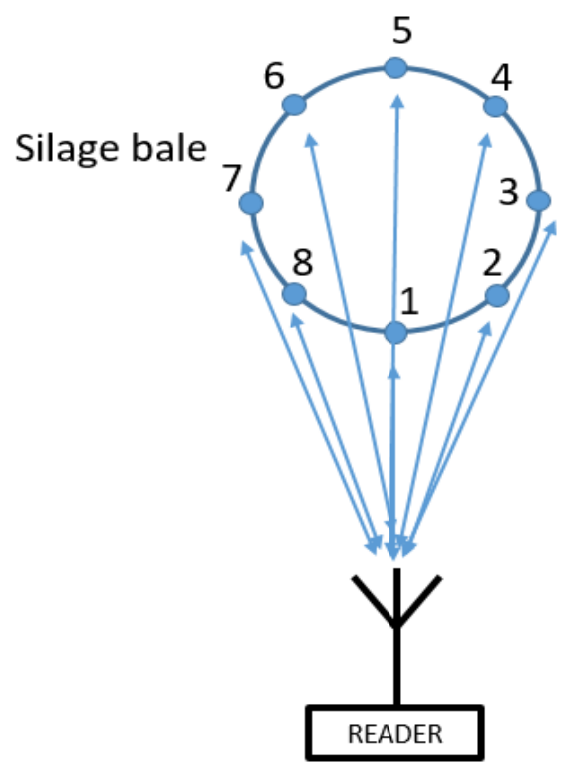

Fig. 7 Measuremnt arrangement, top view. 
The identification distance was measured by moving the reader further from the bale, until the transponder inside the wrapping was no longer backscattering its identification code to the reader.

\subsection{Automated Field Tests: Methodology}

After manual measurements were finished succesfully, the identification and measuring system were integrated to tractor and baler. The reader

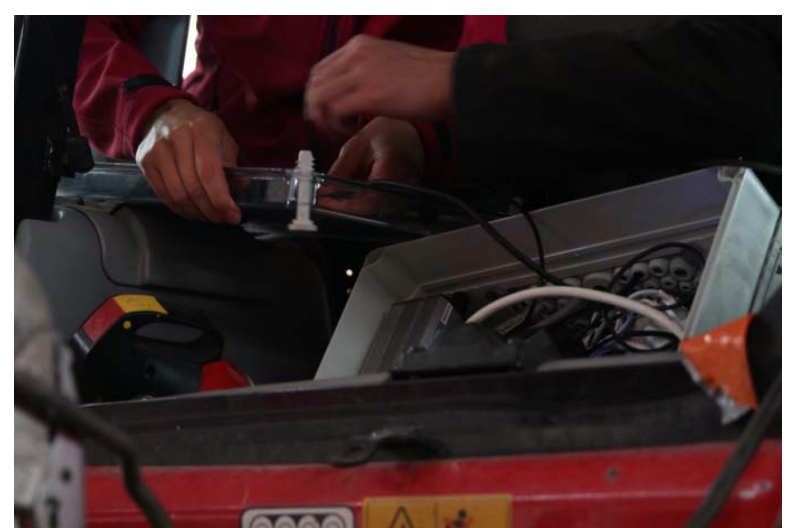

(a)
(Sampo S2 by Nordic ID) and other hardware were placed in IP cassified box in the rear of the tractor, as Fig. 8 shows. The system were powered by tractor, so separate battery was not needed. RFID antenna cable was led via tractor-baler axel to the baler, until the antenna, which was placed on a baler's support beam, as shown in Fig. 9. As antenna cable is rather fragile coaxial cable, it will not tolerate strong bending. Cable was attached tractor-baler other cabling, mounted

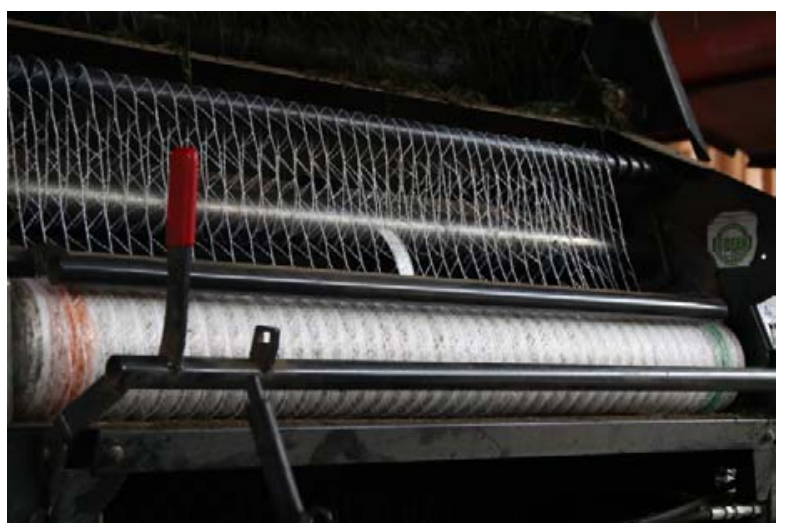

(b)

Fig. 8 Reader setup in the rear of the tractor (a) and silage bale net with passive RFID tags (b).

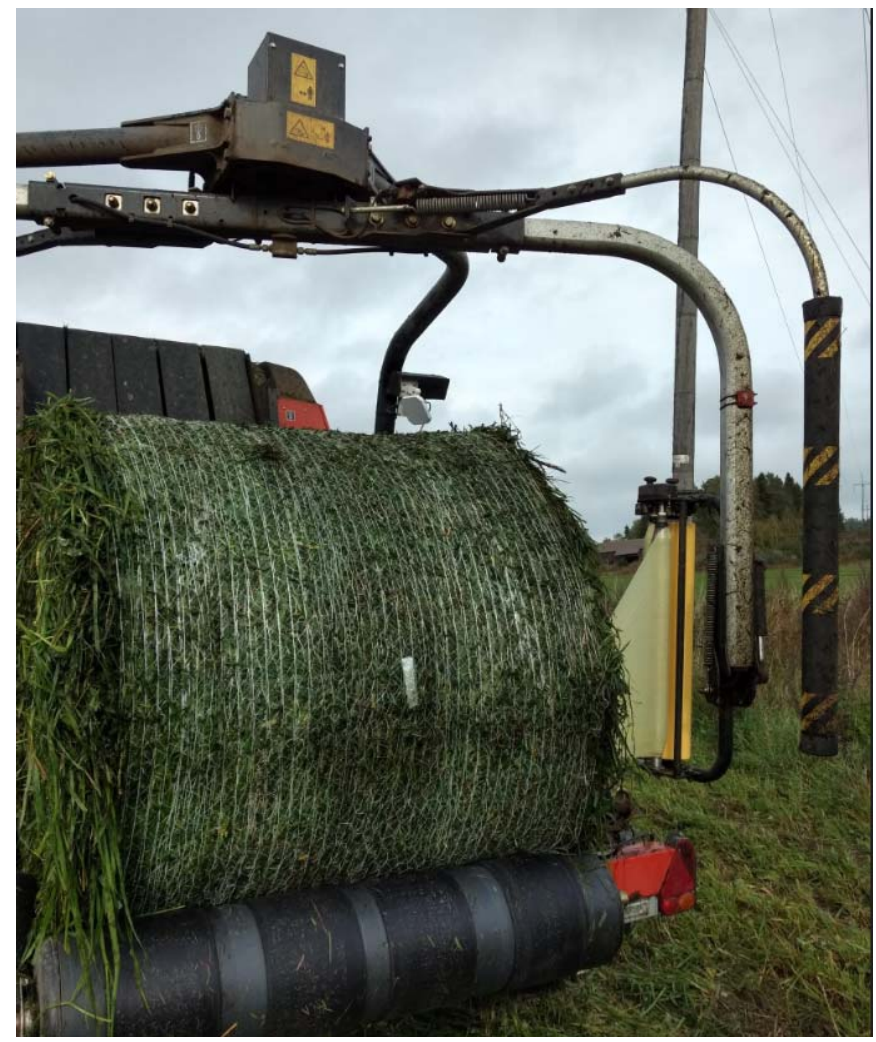

Fig. 9 Silage bale net with integrated RFID transponder (front), and reader antenna in back (white box). 
further in baler side structure, and finally attached again to the baler's pillar structure. For field thests, normal bale net was replaced with a modified net, where the RFID transponders were fixed on every 10 $\mathrm{m}$ with plastic film with strong adhesive.

Aside of unique bale identification, the aim is to collect silage bale specific temperature and relative humidity data, and also harvesting location. Next step will be adding the last seen loaction also in the database, which enables that all bales are visible all the time, throughout their lifecycle. This arrangement requires that farmers have multple RFID readers in different working phases: in baling process, in logistics and in cow houses. Every step is coducted in close co-operation with a group of farmers, i.e., innovation group of EIP-Agri Digibale project and transparently to farmer's community and stakeholders.

\section{Results and Discussion}

This section introduces and analyses measurement results for both manual verification and automated field tests.

\subsection{Manual Measurements}

Manual measurements are the basis of proofing the system operation. By conducting basic performance verification, operation in real baler machine can be estimated, and any nonfunctioning doubts can be verified, and further overcome.

The results for Dogbone transponder measurements are presented in Table 2 . When the reader is facing the transponder (position 1 in Fig. 7), or being in small angle against it (positions 2 and 8), the transponders are identified with sufficient distance. On the other hand, at opsitions 3 and 7, the transponder edge is facing the reader antenna, and the transponder antenna is not facing the transmitted wave. Therefore, transponder identification is not achieved with any distance. In positions 4, 5 and 6, the transmitted wave should propagate through the silage bale, which causes too much reflections and refractions, so that the electromagnetic wave elopes to its surroundings, and further attenuates in a way that the harvested wave does not give sufficient amount of energy to the transponder microchip to wake up and recognize the reader request.

\subsection{Automated Field Tests}

The results of automated RFID transpoder field tests are presented in Figs. 10 and 11. These results are based on three test runs, where all the transponders were identified succesfully. Fig. 10 gives a general map in the area of frarmers' fields. The left corner of the figure shows, that totally 151 silage bales have been identified. Fig. 11 shows more closer look to the application software, and shows detailed location, and transponder related information on the left side of the map. Green circles in the map presents succesfully identified transponders, while red dots are intentionally marked as fault ones. Nevertheless, this operation was manually tested to demonstrate farmer's possiblitiy to add faulty mark to system in any problematic case, such as birds or rodents causing holes to bale's plastic layers.

Table 2 Manual measurement results in silage bale.

\begin{tabular}{lll}
\hline $\begin{array}{l}\text { Transponder position in bale according to } \\
\text { Fig. } 7\end{array}$ & $\begin{array}{l}\text { Simultaneous identification of multiple } \\
\text { transponders, OK/NOK }\end{array}$ & $\begin{array}{l}\text { Maximum transponder identification } \\
\text { distance, mm }\end{array}$ \\
\hline 1 & OK & 3,800 \\
2 & OK & 1,700 \\
3 & NOK & 0 \\
4 & NOK & 0 \\
5 & NOK & 0 \\
6 & NOK & 0 \\
7 & NOK & 0 \\
8 & OK & 3,600 \\
\hline
\end{tabular}




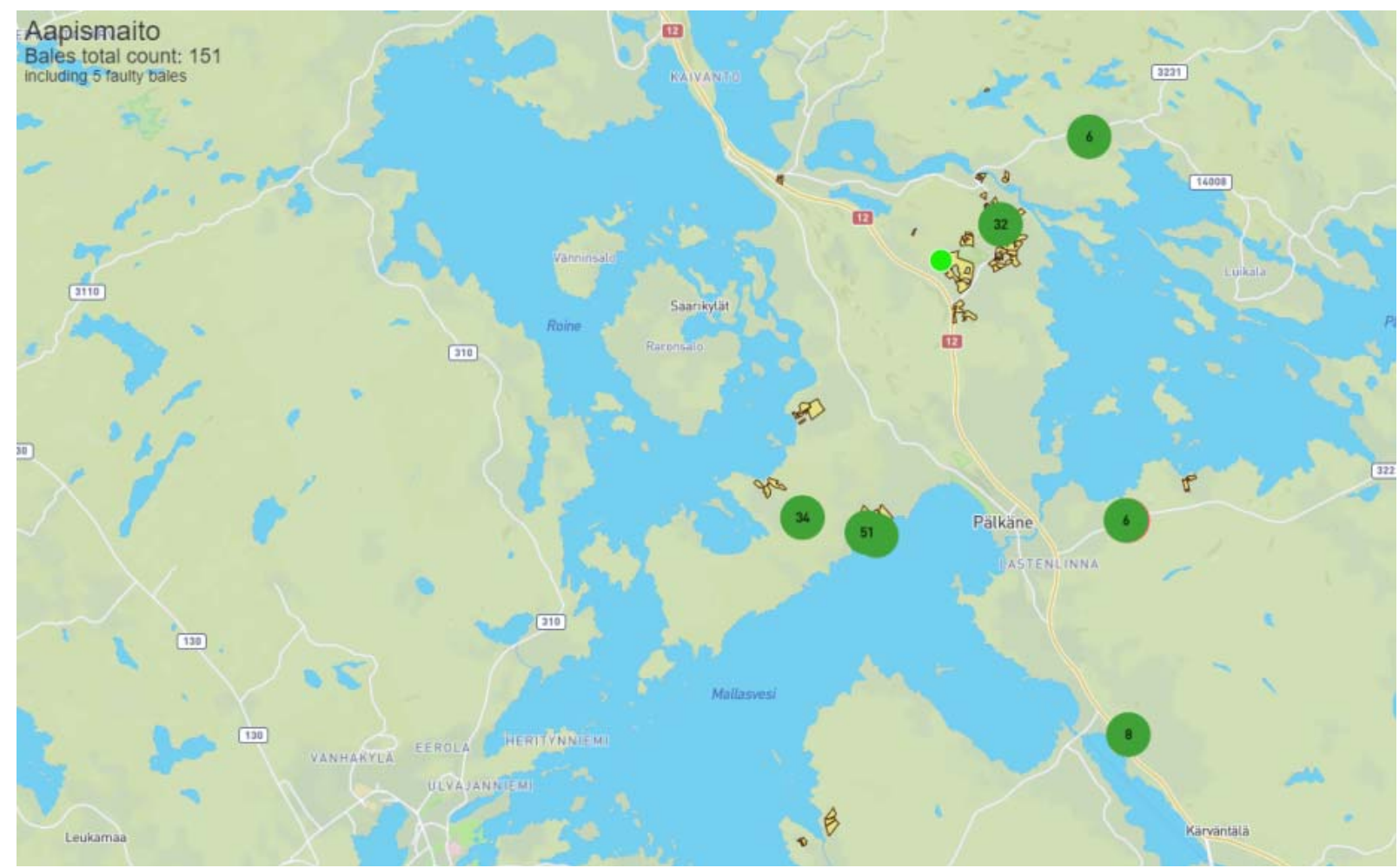

Fig. 10 Overview map of Digibale application/A. Juntunen HAMK.

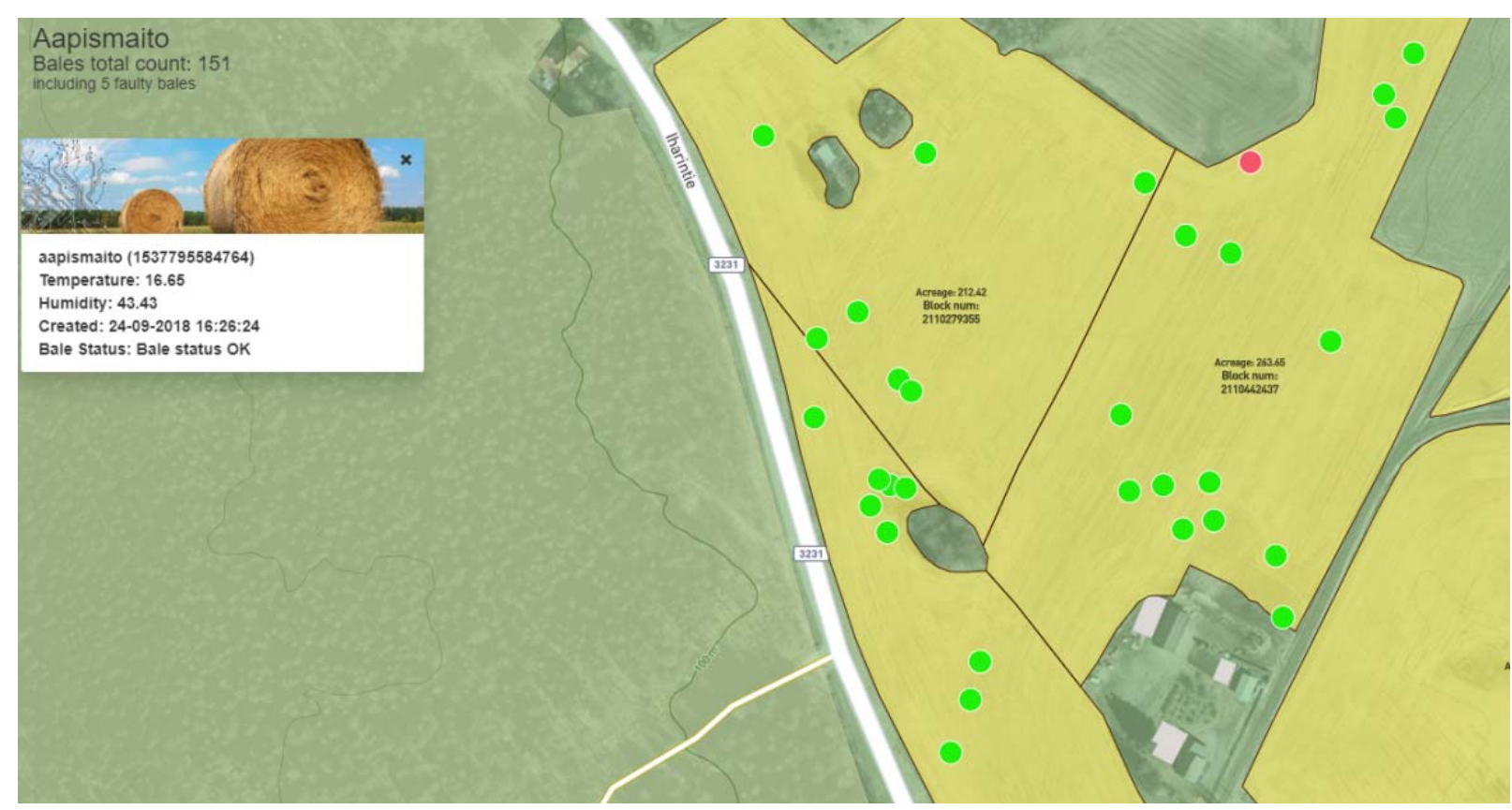

Fig. 11 Zooming of Digibale map and unique bale information/A. Juntunen HAMK.

\subsection{Discussion}

The results achieved in this research show that passive RFID technology suits well to the identification of silage bales. Both manual measurements in stationary environmental conditions and automated field tests in varying environmental conditions were conducted successfully, despite of stationary identification of full 360 degrees. In real application this lack was not seen a problem, as the bale is rotating in baler machine 
during the wrapping procedure, enabling continuous transponder identification throughout.

In future work, this lack must be however considered carefully, as in manual treatment of silage bales, e.g., when moving bales from field to cow house, the tractor clamps may both need a reader antenna. The costs for an extra antenna are however rather low, less than $€ 100$, making the investment acceptable.

\section{Conclusions}

The results presented in this paper indicate that passive RFID technology is suitable for unique silage bale identification. Manual application measurements, where the transponders were attached to areal silage bale, between the silage and plastic wrapping, showed sufficient performance over 90 degrees angle, or $1 / 4$ of bale, at $1.7 \mathrm{~m}$ distance from bale edge. In addition, point-to-point identification, in 0 degree angle, gave maximum of $3.8 \mathrm{~m}$ identification distance. In addition, automated field test showed excellent performance with $100 \%$ identification certainty, with 151 transponder population. These results give good starting point to upcoming durability testing, where transponders' operation over Finnish winter condition is verified.

As next steps for the Digibale concept develompent and piloting are durability testing over wintertime, hardware improvemenet and multiple location stamps addition to database. Passive RFID transponders for challenging applications have been studied for many years, though based on author's best knowledge, silage bale transponder has not yet published or commercialized.

\section{Acknowledgments}

Authors would like to express their gratitude to Finnish Countryside Innovation Group (EIP) and Finnish Ministry of Agriculture and Forestry due to funding this project. In addition, authors are thankful to BSc Khoa Dang and Mr. Bao Tran from HAMK for assisting the practical measurement part of this research.

\section{References}

[1] McDonald, P., Henderson, A. R., and Heron, S. J. E. 1991. The Biochemistry of Silage (2nd ed.). Aberystwyth: Chalcombe Publications.

[2] Digibale Project 2018-2020. 2018. "Digibale—Efficiency in Life Cycle Control of Forage Bales.” Luke, Natural Resources Institute Finland. Assessed May 21, 2018. https://www.luke.fi/en/projects/digipaali/.

[3] RFID in Europe. 2012. "Standards and Regulations." Accessed May 28, 2019. http://www.rfidineurope.eu/SR.

[4] Bolomey, J. C., Capdevila, S., Jofre, L., and Romeu, J. 2010. "Electromagnetic Modeling of RFID-Modulated Scattering Mechanism. Application to Tag Performance Evaluation.” Proceedings of the IEEE 98: 1555-69.

[5] Pouzin, A., Vuong, T. P., Tedjini, S., Pouyet, M., Perdereau, J., and Dreux, L. 2009. "Determination of Measurement Uncertainties Applied to the RCS and the Differential RCS of UHF Passive RFID Tags.” In Antennas and Propagation Society International Symposium, APSURSI '09, IEEE, 1-4.

[6] She, K., He, Y., Li, B., Hou, Z., Zhu, Y., and Zuo, L. 2010. "Theory and Measurement of Delta RCS for RFID Tag on Various Materials.” In 6th International Conference on Wireless Communications Networking and Mobile Computing, WiCOM, 1-4.

[7] Finkenzeller, K. 2003. RFID Handbook (2nd ed.). John West Sussex, UK: Wiley \& Sons Inc.

[8] Keskilammi, M., Sydänheimo, L., and Kivikoski, M. 2003. "Radio Frequency Technology for Automated Manufacturing and Logistics Control. Part 1: Passive RFID Systems and the Effects of Antenna Parameters on Operational Distance." International Journal on Advanced Manufacturing Technology 21 (10-11): 769-74.

[9] Hansen, R. 1989. "Relationships between Antennas as Scatterers and as Radiators.” Proceedings of IEEE 77 (5): 659-62.

[10] Pozar, D. 2004. "Scattered and Absorbed Powers in Receiving Antennas.” IEEE Antennas Propagation Magazine 46 (1): 144-5.

[11] Sydänheimo, L., Nummela, J., Ukkonen, L., McVay, J., Hoorfar, A., and Kivikoski, M. 2008. "Characterization of Passive UHF RFID Tag Performance.” IEE Antennas and Propagation Magazine 50: 207-12.

[12] Keskilammi, M. 2004. "Importance of Application Specific Antennas on Passive Long-Range RFID System Performance.” Ph.D. dissertation, Tampere University of Technology Publications 516, TTY-Paino, Tampere, 
Finland

[13] Rao, K., Duan, D.-W., and Heinrich, H. 1999. "On the Read Zone Analysis of Radio Frequency Identification Systems with Transponders Oriented in Arbitrary Directions.” Proceedings of Microwave Conference 3: 758-61.

[14] Fuschini, F., Piersanti, C., Paolazzi, F., and Falciasecca, G. 2008. "Analytical Approach to the Backscattering from UHF RFID Transponder.” Antennas and Wireless Propagation Letters IEEE 7: 33-5.

[15] Vizmuller, P. 1995. RF Design Guide: Systems, Circuits and Equations. Boston, USA: Artech House.

[16] Appel-Hansen, J. 1988. “Accurate Determination of Gain and Radiation Patterns by Radar Cross-Section Measurements.” IEEE Transactions on Antennas and Propagation 27 (5): 640-6.

[17] Nikitin, P. V., and Rao, K. V. S. 2006. "Theory and Measurement of Backscattering from RFID Tags.” IEEE Antennas and Propagation Magazine 48: 212-8.

[18] Reitz, J., Milford, F., and Christy, R. 1962. Foundations of Electromagnetic Theory. New York, USA: Addison-Wesley, Boston Addison-Wesley Publishing Company Inc.

[19] Ukkonen, L., Soini, M., Engels, D., Sydänheimo, L., and Kivikoski, M. 2004. "Effect of Conductive Material in Objects on Identification with Passive RFID Technology:
A Case Study of Cigarette Cartoons.” In the International Conference on Machine Automation, 569-72.

[20] Byun, J.-K., Choi, N.-S., and Kim, D.-H. 2012. “Optimal Design of a RFID Tag Antenna Based on Plane-Wave Incidence.” IEEE Transactions on Magnetics 48: 795-8.

[21] Cho, C., Park, I., and Choo, H. 2009. "Design of a Circularly Polarized Tag Antenna for Increased Reading Range." IEEE Transactions on Antennas and Propagation 57: 3418-22.

[22] Lee, B. 2008. "Review of RFID Tag Antenna Issues at UHF Band." In Microwave Conference 2008. APMC 2008. Asia-Pacific, 1-4.

[23] Tang, Z., He, Y., Hou, Z., and Li, B. 2009. “The Effects of Antenna Properties on Read Distance in Passive Backscatter RFID Systems.” In International Conference on Networks Security Wireless Communications and Trusted Computing, NSWCTC'09, volume 1, 120-3.

[24] Alonso, M., and Finn, E. 1967. Fundamental University Physics. Vol. II: Fields and Waves. Reading, MA, USA: Addison-Wesley Publishing Company, 556.

[25] Kraus, J. 1950. Antennas. New York, USA: McGraw-Hill International Editions.

[26] Nikitin, P. V., and Rao, K. V. S. 2008. "Antennas and Propagation in UHF RFID Systems.” In IEEE International Conference on RFID, 277-88. 